\title{
¿Es posible hacer cumplir la ley sin sancionar? Aplicando de manera «responsiva» la regulación en el Perú, a propósito del caso de abogacía de la competencia sobre las barreras burocráticas en el mercado de servicios públicos \\ Is it possible to enforce the law without sanctioning?: Applying regulation with a "responsive" approach in Peru, with regard the advocacy strategy about the bureaucratic barriers in the market of public utilities
}

\section{FRANCISCO OCHOA MENDOZA*}

Resumen: Una regulación costosa y excesiva puede afectar negativamente la cantidad de ofertantes en el mercado, al desincentivar su acceso y/o permanencia en él. No obstante ello, en el mundo existen pocos mecanismos de defensa de la competencia que controlen este tipo de actividad. El presente artículo describe brevemente el mecanismo de control regulatorio empleado en el Perú a través de la Comisión de Eliminación de Barreras Burocráticas del Indecopi, la cual ha logrado en menos de 3 años la eliminación voluntaria de más de 1000 regulaciones y trabas administrativas que afectaban, entre otros, el mercado de infraestructura en servicios públicos, a través de una estrategia que prescinde del uso exclusivo de procedimientos sancionadores y privilegia la coordinación con los agentes regulados para lograr el cumplimiento efectivo de la ley. El desarrollo de esta estrategia, a su vez, permite demostrar la posibilidad de aplicar un nuevo estilo de «enforcement» en el Perú, que ha sido estudiado y adoptado en otros países del mundo, como es la «Regulación Responsiva».

Palabras clave: regulación - competencia - análisis de impacto regulatorio - abogacía de la competencia - servicios públicos - barreras burocráticas - regulación responsiva - enforcement

Abstract: Expensive and excessive regulations may affect the number of firms by discouraging them to access and remain into the market. Despite of such a fact, worldwide there are few legal mechanisms within competition law able to control regulatory activity. This document describes briefly the Peruvian

* Abogado por la Universidad de Lima, Perú, y Máster en Regulación con especialización en Servicios Públicos por la London School of Economics and Political Science, Reino Unido. Es profesor de la Maestría de Regulación en Servicios Públicos de la Pontificia Universidad Católica del Perú y de la Escuela de Posgrado de la Universidad del Pacífico. Es docente de la Escuela Nacional de la Competencia y ha sido profesor del curso de Derecho Administrativo en la Universidad Peruana de Ciencias Aplicadas. Actualmente, es Subjefe de la Secretaría Técnica de la Comisión de Eliminación de Barreras Burocráticas del INDECOPI. Las opiniones vertidas en el presente documento no comprometen en modo alguno a las instituciones antes mencionadas. Correo electrónico: fochoamendoza@me.com 
mechanism of regulatory oversight through the Indecopi's Elimination of Bureaucratic Barriers Commission, which has reached in less than 3 years the voluntary elimination of more than 1000 regulatory and administrative burdens affecting, inter alia, the market of the deployment of infrastructure on public utilities. This has been the result of a strategy that not relies on sanctioning administrative procedures but in a coordinative-oriented approach with the regulatees aiming to reach the effective accomplishment of the law. In turn, the development of such a strategy make possible to show a new style of enforcement in Peru, which has been studied and undertaken in other countries around the world, namely "Responsive Regulation".

Key words: regulation - competition regulatory impact assessment - competition advocacy - public utilities - bureaucratic barriers - responsive regulation - enforcement

\begin{abstract}
CONTENIDO: I. INTRODUCCIÓN.- II. IMPACTO DE LA ACTIVIDAD REGULATORIA EN LA COMPETENCIA.- III. ABOGACÍA DE LA COMPETENCIA Y CONTROL REGULATORIO.- IV. FUNCIONES ASIGNADAS LEGALMENTE A LA CEB DEL INDECOPI.- V. PROBLEMÁTICA DE LAS REGULACIONES MUNICIPALES EN SERVICIOS PÚBLICOS.- VI. "REGULACIÓN RESPONSIVA»: FUNDAMENTOS Y PRINCIPIOS.- VII. ESTRATEGIA «RESPONSIVA» DE LA CEB Y RESULTADOS OBTENIDOS.- VIII. CONCLUSIONES.- IX. BIBLIOGRAFÍA.
\end{abstract}

\title{
I. INTRODUCCIÓN
}

En el mes de marzo de 2016, el Perú fue anunciado como ganador de un concurso a nivel mundial. No se trataba de una competencia deportiva, gastronómica o de patrimonio cultural. Se trató de un certamen organizado por el Banco Mundial y la Red Internacional de Competencia $(\mathrm{ICN})^{1}$ que, desde el año 2014, convoca a todas las autoridades de competencia alrededor del mundo a presentar casos exitosos sobre «abogacía de la competencia».

La práctica ganadora consistió en una estrategia adoptada por una de las oficinas del Instituto Nacional de Defensa de la Competencia y de la Protección de la Propiedad Intelectual (INDECOPI) — la autoridad de competencia peruana-, la cual utilizó métodos de «persuasión» y «coordinación» en sustitución del uso exclusivo de los mecanismos de «castigo» o «sanción» para lograr el cumplimiento efectivo de la ley a su cargo. Los resultados obtenidos en menos de tres años fueron sorprendentes: casi 1000 supuestos de cambio en el comportamiento regulatorio respecto de barreras que frenaban la inversión, entre otros

1 Las siglas corresponden a su nombre en inglés: International Competition Network. La ICN es una red de agencias de competencia de 92 jurisdicciones cuyo objetivo principal es la promoción de buenas prácticas de la competencia. Para mayor detalle, véase ICN (2009a). 
sectores $^{2}$, en el mercado de servicios públicos (telecomunicaciones, suministro de agua, electricidad y gas natural) sin que fuera necesaria la imposición de multas. Esta estrategia no solo es interesante por la novedad de su diseño frente a la metodología de sanción automática por incumplimiento de la ley —utilizada usualmente por las autoridades administrativas_-, sino que podría cambiar la lógica del enforcement a nivel nacional.

La referida estrategia — probablemente aplicada por primera vez en el Perú— posee ciertos elementos de la llamada «regulación responsiva» ${ }^{3}$ (Ayres \& Braithwaite, 1992; Braithwaite, 2011), la cual ha sido utilizada en Reino Unido y en Australia como técnica de enforcement (Ivec \& Braithwaite, 2015) ${ }^{4}$. Según esta forma de regulación, el regulador debe recurrir inicialmente a métodos de «diálogo» y «coordinación» con el regulado, utilizando herramientas más coercitivas solo como último recurso, a manera de escalamiento de una pirámide de cumplimiento.

El presente artículo pretende explicar brevemente de qué manera se construyó la mencionada estrategia de la Comisión de Eliminación de Barreras Burocráticas $(\mathrm{CEB})^{5}$ del INDECOPI, así como los resultados obtenidos, con énfasis en la defensa de la competencia y la supervisión de regulaciones. Para ello es necesario desarrollar seis temas básicos. En primer lugar, debe explicarse cuál es el impacto de la actividad regulatoria en la competencia, de tal manera que, en segundo lugar, pueda entenderse la importancia de las prácticas de abogacía de la competencia y de mecanismos de control regulatorio. En tercer lugar, se discutirá brevemente las funciones de supervisión regulatoria asignadas a la CEB del INDECOPI, así como las herramientas legales con las que cuenta (las cuales son únicas en el mundo). En cuarto lugar, se hará referencia a la problemática regulatoria — a nivel local— en el sector de servicios públicos, lo cual ameritó la intervención de la CEB. En quinto lugar, se identificará los elementos más importantes de la teoría de la «regulación responsiva» (desarrollada principalmente por John Braithwaite), los cuales se relacionan con la estrategia

2 Los otros sectores analizados fueron, entre otros, los de construcción y actividades comerciales, afectados por la imposición de trabas en la obtención de licencias de edificación, habilitación urbana, de funcionamiento y la autorización para la ubicación de anuncios.

3 Adaptación al español del término «Responsive Regulation». La palabra «responsive», en idioma inglés, significa «dar una respuesta positiva o reaccionar rápidamente a algo o alguien» (Cambridge University Press, 2016).

4 En esta obra, las autoras identifican los distintos sectores en los que ha sido utilizado el modelo de «escalamiento de pirámide» de la regulación responsiva (salud, transporte, bioseguridad, seguridad en el trabajo, entre otros).

5 Debe precisarse que la referida estrategia fue ideada y desarrollada por el personal de la Secretaría Técnica de la CEB. Sin embargo, en el presente documento, la referencia a la CEB involucrará indistintamente tanto a la Comisión como a su Secretaría Técnica. Esto último, teniendo en cuenta que las secretarías técnicas dependen funcionalmente de las comisiones y que constituyen órganos de apoyo en la tramitación e investigación de los procedimientos que el órgano resolutivo tiene a su cargo, conforme a los artículos 43 y 44 del decreto legislativo 1033 (2008).

¿ES POSIBLE

HACER CUMPLIR

LA LEY SIN

SANCIONAR?

APLICANDO DE

MANERA

«RESPONSIVA» LA

REGULACIÓN EN

EL PERÚ

IS IT POSSIBLE

TO ENFORCE THE

LAW WITHOUT

SANCTIONING?:

APPLYING

REGULATION

WITH A

"RESPONSIVE" APPROACH IN

PERU 
adoptada por la CEB en sus investigaciones. Finalmente, en sexto lugar, se explicará las particularidades de la mencionada estrategia, la cual ha hecho posible la eliminación voluntaria de regulaciones innecesarias sin el uso de sanciones.

\section{IMPACTO DE LA ACTIVIDAD REGULATORIA EN LA COMPETENCIA}

El derecho de la competencia tiene por objeto, principalmente ${ }^{6}$, buscar el bienestar del consumidor y la eficiencia económica del mercado (Hovenkamp, 1985, pp. 226-229; Bork, 1993, pp. 90-91, 426-429; Jones \& Sufrin, 2014, pp. 4, 12-13) ${ }^{7}$ a través de la represión de comportamientos que restrinjan la existencia de nuevos competidores y/o que distorsionen las condiciones de los ofertantes. Tradicionalmente, la legislación sobre defensa de la competencia está enfocada en el comportamiento de los agentes privados, como si estos fuesen los únicos capaces de afectar la existencia o mantenimiento de un mercado competitivo. Como consecuencia de ello, las autoridades de competencia a nivel mundial dirigen sus esfuerzos hacia el monitoreo de prácticas abusivas de posición dominante, los acuerdos entre empresas sobre las condiciones del producto o servicio y, en algunos casos, el control de las concentraciones empresariales.

Sin embargo, el comportamiento de los agentes públicos —a través de la producción de regulaciones - también tiene un impacto importante en la competencia. En efecto, cuando las autoridades ejercen sus poderes regulatorios al imponer reglas de juego o cargas administrativas sobre los agentes que pretenden ofertar un bien o producto en el mercado, existe un efecto en la cantidad de ofertantes (Emberger, 2006; OECD, 2008). Esto se debe a que (i) algunas empresas encuentran muy difícil asumir los costos de cumplimiento de una regulación para ingresar formalmente a un mercado o para permanecer en él (en el caso de los competidores ya existentes); (ii) es poco probable que la regulación sea cumplida por razones extraeconómicas; (iii) la regulación prohíbe de manera absoluta la actividad; o (iv) la autoridad asigna con carácter exclusivo la posibilidad de desarrollar una actividad económica.

6 Si bien esta finalidad es aceptada mayoritariamente, no es la única reconocida por la literatura y las autoridades en materia de defensa de la competencia, ya que se identifican otros objetivos, tales como la «dispersión del poder de mercado», la «protección de los pequeños competidores y la estructura del mercado", la "promoción de fines socio-políticos» (impacto en el empleo al analizar una fusión, por ejemplo), entre otros (Jones \& Sufrin, 2014, pp.15-19; OECD, 2003).

7 En nuestra legislación, se reconoce expresamente este objetivo en el artículo 1 del decreto legislativo 1034 (2008). Para un mejor desarrollo el tema, véase Quintana (2011). 
A manera de ejemplo, cuando una municipalidad obliga a que todo restaurante tenga un mínimo estándar de lujo a través de la categoría de 3, 4 o 5 «tenedores» ${ }^{8}$, indirectamente genera que los empresarios que no puedan asumir los costos de dicha regulación se abstengan de ingresar a este mercado 9 . Esto, a su vez, origina que el mercado de restaurantes en el distrito, objeto de la regulación, se encuentre concentrado, ya que estará conformado únicamente por las empresas con la capacidad económica para cubrir los costos de la regulación. Del mismo modo, cuando la autoridad de salud exige que en el mercado de venta de oxígeno medicinal se comercialice únicamente el producto que tenga una concentración de pureza mínima del 99\% al 100\% (pese a que el grado usado y comercializado regularmente es a partir de $93 \%)^{10}$, indirectamente excluye del mercado a los competidores que no son capaces de asumir el costo de la nueva regulación ${ }^{11}$.

La imposición de cargas administrativas para la obtención de autorizaciones también puede llevar a la imposibilidad de ser habilitado legalmente para ingresar al mercado o permanecer en él. Así, por ejemplo, cuando las municipalidades regulan el procedimiento para autorizar el despliegue de infraestructura a cargo de empresas prestadoras de servicios públicos (telecomunicaciones, suministro de agua, electricidad y gas natural, entre otros), la cantidad y costo de la documentación e información requerida puede originar que los operadores del servicio se vean desincentivados o impedidos de obtener las respectivas autorizaciones y, por tanto, no puedan desarrollar legalmente sus actividades.

Una regulación costosa no es el único supuesto de una práctica con impacto en la competencia. Cuando las autoridades públicas exigen requisitos de imposible o difícil cumplimiento, o cuando establecen prohibiciones para el desarrollo de una actividad, ni la capacidad

8 En la legislación nacional, la categorización del número de «tenedores» es voluntaria y quienes deseen adoptarla deben contar con equipamiento mínimo en la infraestructura de sus restaurantes (como el hecho de tener como mínimo un ascensor, una sala de espera con bar), así como demostrar ciertas características del personal (tener jefes de cocina y de comedor por separado, personal uniformado) o del material de la vajilla, entre otros aspectos. Al respecto, véase Ministerio de Comercio Exterior y Turismo (2004, anexo 3). El listado de completo de estos requerimientos se encuentra en el Anexo 3 del Reglamento de Restaurantes, aprobado por Decreto supremo 025-2004-Mincetur. Al respecto, véase Ministerio de Comercio Exterior y Turismo (2004).

9 Una regulación similar fue objeto de análisis por parte de la CEB en algunos distritos de Lima Metropolitana, habiéndola declarado ilegal por contravenir el derecho a la libertad de empresa, reconocido en el decreto legislativo 757. Para mayor detalle, véase las resoluciones 3065-2010/ SC1-INDECOPI Y 0017-2014/CEB-INDECOPI.

10 Este tipo de regulación fue evaluada por la CEB y considerado como irrazonable, en tanto el Ministerio de Salud no pudo sustentar la necesidad y proporcionalidad de la medida en función del interés público protegido. Para mayor detalle, véase las resoluciones 0334-2012/CEB-INDECOPI y 1232-2013/SDC-INDECOPI.

11 De acuerdo a información de las empresas denunciantes en el expediente 000151-2010/CEB, el tipo de oxígeno exigido por el Ministerio de Salud solo podía ser suministrado por 5 empresas dentro del mercado local. Véase resolución 0334-2012/CEB-INDECOPI.

¿ES POSIBLE

HACER CUMPLIR

LA LEY SIN

SANCIONAR?

APLICANDO DE

MANERA

«RESPONSIVA» LA

REGULACIÓN EN

EL PERÚ

IS IT POSSIBLE

TO ENFORCE THE

LAW WITHOUT

SANCTIONING?:

APPLYING

REGULATION

WITH A

"RESPONSIVE"

APPROACH IN

PERU 
económica del empresario puede ser suficiente para ingresar al mercado o permanecer en él. En efecto, existen casos en los que municipalidades exigen que las empresas operadoras de servicios públicos (o los titulares de la infraestructura pasiva) cuenten con la aceptación de los vecinos de la zona para la instalación de estaciones base de telecomunicaciones en bienes de propiedad privada ${ }^{12}$, pese a que cuentan con el permiso del propietario del inmueble. Si la empresa no logra conseguir dicho documento, la autorización es denegada y, en consecuencia, no estará habilitada para realizar la obra que le permitirá prestar el servicio público o la actividad de arrendamiento de la infraestructura. Otro caso similar se presenta cuando una autoridad local prohíbe la instalación de antenas de telefonía móvil en determinadas zonas $^{13}$ (o en todo el distrito en el que no existe cobertura del servicio), con lo cual se restringe la posibilidad de que las empresas desarrollen sus actividades en el mercado.

Las regulaciones prohibitivas pueden originar, a su vez, que aquellos que ya se encuentran posicionados en el mercado - a quienes no se les aplica esta nueva regla - se beneficien con la imposibilidad de afrontar nuevos competidores. Un ejemplo de ello es la decisión, que ha sido adoptada por el Ministerio de Transportes y Comunicaciones (MTC) desde hace más de 6 años, de suspender el otorgamiento de nuevas autorizaciones para prestar el servicio público de transporte de personas a nivel nacional ${ }^{14}$. Esta práctica genera que las empresas de transporte que fueron autorizadas con anterioridad a la decisión se mantengan en un mercado con reducida competencia.

Finalmente, las regulaciones que asignan exclusividades a ciertos agentes tienen un evidente impacto en la competencia. Un ejemplo de ello es la regulación que fuera emitida por la Municipalidad Metropolitana de Lima (MML) en la que se asignó la exclusividad a una empresa para prestar el servicio de revisiones técnicas dentro de la provincia de Lima $^{15}$. Dicha decisión fue luego mantenida por el MTC al momento

12 Este tipo de regulación fue evaluada por la CEB y fue considerado como ilegal por contravenir la normativa nacional. Para mayor detalle, véase la resolución 0340-2015/SDC-INDECOPI.

13 Este tipo de regulación fue evaluado por la CEB en algunos distritos de Lima Metropolitana y en el interior del país y fue declarado ilegal por contravenir la normativa nacional que promueve la instalación de infraestructura en servicios públicos. Para mayor detalle, véase las resoluciones 00192007/CAM-INDECOPI, 1493-2007/TDC-INDECOPI y 0513-2015/SDC-INDECOPI.

$14 \mathrm{La}$ CEB se ha pronunciado sobre este tipo de medida en diversas oportunidades. Al respecto, véase las resoluciones 0453-2015/CEB-INDECOPI, 0143-2014/CEB-INDECOPI, 0170-2014/CEB-INDECOPI, 0194-2015/CEB-INDECOPI, 0284-2015/SDC-INDECOPI, 0271-2015/SDC-INDECOPI, 0226-2015/ SDC-INDECOPI y 0188-2015/SDC-INDECOPI, entre otras.

15 Se trató de la ordenanza 694, modificada por la ordenanza 1064, a través de la cual la MML estableció que el servicio de revisiones técnicas en Lima sea prestado exclusivamente por la empresa Lidercon Perú S.A.C. Este caso fue evaluado por la CEB mediante la resolución 0013-2008/CAM-INDECOPI, confirmada por el Tribunal del INDECOPI con la resolución 1692-2008/TDC-INDECOPI. 
de denegar las autorizaciones solicitadas por diversas empresas para participar en el mercado de revisiones técnicas ${ }^{16}$.

\section{ABOGACÍA DE LA COMPETENCIA Y CONTROL REGULATORIO}

Pese a que las prácticas regulatorias pueden afectar al mercado y a la cantidad de ofertantes, la legislación sobre defensa de la competencia usualmente no incluye métodos punitivos para estos supuestos, sino que ofrece un mecanismo de naturaleza consultiva y de persuasión, denominado abogacía de la competencia. Esta labor involucra a todas aquellas actividades —-desarrolladas por la autoridad de competencia- dirigidas a promover un ambiente competitivo para las actividades económicas a través de mecanismos no coercitivos, lo cual supone convencer a otras entidades públicas de abstenerse de adoptar medidas innecesarias que afecten la competencia (ICN, 2002, pp. i-iii).

La abogacía de la competencia es considerada como una herramienta complementaria a los mecanismos coercitivos aplicados sobre los agentes privados que infringen las reglas de competencia (Emberger, 2006). Sin embargo, una de las principales limitaciones de esta labor consiste en que, usualmente, las recomendaciones realizadas sobre el carácter anticompetitivo de una regulación no son vinculantes para el agente regulador (ICN, 2009a; 2009b, pp. 7-8). En ese sentido, la adopción de las recomendaciones depende principalmente del poder de la persuasión de la autoridad de competencia. De ahí que surge una interrogante válida: si la actividad regulatoria es capaz de afectar y distorsionar las condiciones de competencia, ipor qué no existe un mecanismo por el cual los agentes reguladores se encuentren obligados a adoptar las recomendaciones de la autoridad de competencia?

El reporte emitido por la ICN el año 2009, señala que, a nivel mundial, los casos de abogacía de la competencia con herramientas vinculantes son mínimos (2009b, pp. 20-21) ${ }^{17}$. Incluso, tales supuestos excepcionales son aplicados de manera ex ante a la implementación de la regulación ${ }^{18} y$, generalmente, involucran la obligación de «tomar en cuenta» ${ }^{19}$ y no de «estar obligado a implementar» la recomendación.

16 Para mayor detalle, véase las resoluciones 0459-2013/CEB-INDECOPI y 0368-2015/CEB-INDECOPI, entre otras.

17 Incluso, de los 32 países analizados en dicho reporte, 13 no tenían facultades legales para exigir información a las entidades públicas en actividades de abogacía (ICN, 2009b, p. 11).

18 Los casos de abogacía vinculante, descritos en el reporte, son los de la India, México y Rumania (ICN, 2009b, p. 21).

19 En estos supuestos, se trata de una obligación de dar respuesta a «por qué no» se implementó la recomendación.

¿ES POSIBLE

HACER CUMPLIR

LA LEY SIN

SANCIONAR?

APLICANDO DE

MANERA

«RESPONSIVA» LA

REGULACIÓN EN

EL PERÚ

IS IT POSSIBLE

TO ENFORCE THE

LAW WITHOUT

SANCTIONING?:

APPLYING

REGULATION

WITH A

"RESPONSIVE"

APPROACH IN

PERU 
Se ha sugerido también que las prácticas de abogacía deben ser fortalecidas con la aplicación del Análisis de Impacto Regulatorio (RIA, por sus siglas en inglés: Regulatory Impact Assesment) a aquellas propuestas normativas que afecten la competencia (Emberger, 2006). El RIA es una herramienta para la búsqueda de la eficiencia y eficacia en la toma de decisiones regulatorias (OECD, 2008). En términos de eficacia, el RIA exige que la alternativa regulatoria escogida sea la necesaria e idónea para alcanzar el objetivo público propuesto, mientras que, en términos de eficiencia, se requiere que los beneficios de la medida sean superiores a los costos que ella involucra. Actualmente, si bien este mecanismo de calidad regulatoria es adoptado en diversos países del mundo (OECD, 2009) ${ }^{20}$, ello no implica necesariamente que su aplicación haya sido adecuada (Hann \& Dudley, 2007; Cecot \& otros, 2008).

Con relación a lo señalado, es importante tener en cuenta que la implementación del RIA sufre de una limitación similar a la del mecanismo de abogacía, ya que las autoridades encargadas de realizar el monitoreo de su cumplimiento no poseen necesariamente poderes coercitivos para implementar sus recomendaciones y, en ningún caso, existe la posibilidad de ordenar el retiro de la regulación y aplicar mecanismos punitivos de manera conjunta.

\section{IV.FUnCIONES ASIGNADAS LEGALMENTE A LA CEB DEL INDECOP|}

Como agencia de competencia, el INDECOPI es una entidad atípica en comparación a sus pares a nivel mundial, no solo porque administra legislación que va más allá de la represión de prácticas anticompetitivas (como las leyes de protección al consumidor, propiedad intelectual, entre otras), sino porque incluye dentro de su estructura orgánica a una autoridad que tiene poder sobre toda regulación y/o actuación proveniente de la administración pública ${ }^{21}$ que afecte el desarrollo de las actividades económicas en el mercado: la CEB.

$\mathrm{LaCEB}^{22}$ del INDECOPI tiene como función principal lograr la eliminación de toda exigencia, requisito, prohibición y/o cobro de la administración pública que afecte el desarrollo de las actividades económicas en el

20 De acuerdo al reporte de la OECD, desde el año 2005, los 31 países miembros han implementado el RIA en sus procesos regulatorios de alguna manera (2009, p. 13).

21 Como se ha señalado en diversos pronunciamientos del INDECOPI, la CEB no es competente para evaluar las disposiciones originadas en leyes, decretos legislativos u otra norma con fuerza de ley, en tanto su ámbito de supervisión no es la función legislativa sino la función administrativa.

22 Antes denominada "Comisión de Acceso al Mercado". Dicho nombre cambia con la vigencia del decreto legislativo 1033. 
mercado y/o que afecte normas de simplificación administrativa ${ }^{23}$. Para cumplir con dicha función, la CEB cuenta, entre otras, con las siguientes atribuciones ${ }^{24}$ :

i. Conocer y evaluar toda modalidad actuación de la administración pública (que incluye a las regulaciones) ${ }^{25}$ que califique como «barrera burocrática» ${ }^{26}$.

ii. Declarar la legalidad y/o razonabilidad de tales actuaciones.

iii. Emitir mandatos de eliminación (general y particular) ${ }^{27}$ de las regulaciones $\mathrm{y} / \mathrm{o}$ actuaciones identificadas como ilegales $\mathrm{y} / \mathrm{o}$ irrazonables, los cuales son vinculantes para toda la administración pública.

iv. Imponer sanciones a los servidores públicos y entidades que desacaten sus mandatos y/o que infrinjan determinadas leyes y/o precedentes vinculantes ${ }^{28}$.

El modelo de control regulatorio en el Perú a través de la CEB resulta sorprendente y poco convencional. En primer lugar, la mayor parte de sistemas legales pone énfasis en el análisis previo de las regulaciones (a través del RIA) ${ }^{29}$, de modo tal que resulta competencia del Poder Judicial el control posterior de estas disposiciones, una vez implementadas. En el caso del Perú, si bien las entidades están obligadas a justificar sus regulaciones y actuaciones de manera previa a su emisión ${ }^{30}$, esta obligación es supervisada de manera posterior por la $\mathrm{CEB}$, pudiendo

¿ES POSIBLE HACER CUMPLIR LA LEY SIN SANCIONAR? APLICANDO DE MANERA «RESPONSIVA»LA REGULACIÓN EN

EL PERÚ

IS IT POSSIBLE TO ENFORCETHE LAW WITHOUT SANCTIONING?: APPLYING REGULATION WITH A "RESPONSIVE" APPROACH IN PERU

23 Función asignada a través del artículo 26BIS del decreto ley 25868 (1992), incorporado por el artículo 50 del decreto legislativo 807 (1996). Esta función también es reconocida en el artículo 23 del decreto legislativo 1033 (2008).

24 Para mayor detalle sobre las atribuciones de la CEB (de eliminación y de sanción), véase Ochoa Mendoza (2015, pp. 45-50).

25 Desde el año 1996 hasta el 2015, el artículo 26BIS del decreto ley 25868 establecía que la competencia de la CEB se limitaba a «actos y/o disposiciones de la administración pública». A partir de la vigencia del decreto legislativo 1212 (2015), que modifica el referido artículo, se amplía el ámbito de competencias de la CEB a «cualquier otra modalidad de actuación» de las entidades de la administración pública.

26 Definición establecida en el artículo 2 de la ley 28996 (2007).

$27 \mathrm{El}$ mandato de eliminación general involucra ordenar que la entidad no aplique — con efectos generales-la barrera identificada por la CEB, mientras que la eliminación particular (o «inaplicación») tiene efectos únicamente respecto de quien presentó una denuncia ante la CEB. Para mayor detalle, véase Ochoa Mendoza (2015, pp. 46-47).

28 Este último caso requiere que la CEB disponga la publicación en el Diario Oficial El Peruano de las resoluciones emitidas en procedimientos de oficio en los que se declara la ilegalidad y/o carencia de razonabilidad de una regulación. Luego de dicha publicación, los servidores que apliquen tales barreras pueden ser sancionados con hasta 20 Unidades Impositivas Tributaria (UIT), conforme al literal c) del artículo 26BIS del decreto ley 25868.

29 Por ejemplo, en el caso de los Estados Unidos de Norteamérica, la Oficina de Información y Asuntos Regulatorios (OIRA, por sus siglas en inglés) realiza una evaluación previa de todas aquellas regulaciones que involucran un impacto económico anual superior a los 100 billones (orden ejecutiva 12866, 1993).

30 Esta obligación se desprende del «principio de razonabilidad» reconocido en el artículo IV del Título Preliminar de la ley 27444 o Ley del Procedimiento Administrativo General (LPAG) (2001) y del artículo 26BIS del decreto ley 25868 , en concordancia con el precedente de observancia obligatoria aprobado mediante resolución 186-97-TDC-INDECOPI (1997). 
ordenarse la eliminación de las regulaciones innecesarias, incluso cuando estas ya han sido implementadas. En segundo lugar, alrededor del mundo, las autoridades encargadas de centralizar la revisión (de manera ex ante) de la adecuada aplicación del RIA no poseen poderes punitivos para hacer exigibles sus decisiones. Inclusive, en muchos casos, el análisis que realizan estas autoridades es considerado como una recomendación sin carácter vinculante.

Cabe señalar que las atribuciones actuales de la CEB han sido producto de una evolución normativa de 20 años $^{31}$, en cuyo proceso estas fueron recortadas ${ }^{32}$ y cuestionadas. Sin embargo, diferentes conformaciones del Congreso de la República ${ }^{33}$ y el propio Tribunal Constitucional (2010) han reconocido la validez e importancia de contar con una autoridad de control regulatorio como la $\mathrm{CEB}$, con prerrogativas suficientes para cumplir su función. De hecho, en los últimos tres años, el Congreso ha reforzado las facultades sancionadoras de la CEB, cuadruplicando la cuantía de multas (de 5 a 20 Unidades Impositivas Tributarias) ${ }^{34}$ y añadiendo mayores supuestos de infracción en materia de barreras burocráticas ${ }^{35}$. El resultado es que actualmente el INDECOPI, a través de la CEB, posee mayores herramientas para intervenir en aquellas regulaciones que afecten innecesariamente el desarrollo del mercado y la competencia.

Teniendo en cuenta el amplio espectro de supervisión que posee la CEB (las entidades de la administración pública a todo nivel de gobierno) ${ }^{36}$ y las extensas atribuciones legales otorgadas, cabe formularse las siguientes interrogantes: (i) icómo es que la CEB prioriza sus esfuerzos de investigación sobre regulaciones presuntamente ilegales y/o irrazonables?, (ii) ide qué manera utiliza sus potestades sancionadoras?, y (iii) ¿qué resultados ha obtenido como consecuencia de sus amplios poderes?

31 Para mayor detalle sobre la evolución histórica de las competencias de la CEB, véase Ochoa Mendoza (2015, pp. 39-45).

32 En efecto, a través de la redacción original del artículo 48 de la LPAG (2001), se dispuso que la CEB no pueda ordenar la eliminación de las barreras contenidas en ordenanzas, sino que únicamente emita informes sobre la legalidad y/o razonabilidad de tales barreras.

33 En el año 2007, a través de la ley 28996, el Congreso retornó las facultades legales que fueron recortadas a la CEB el año 2001 a través de la LPAG. Posteriormente, con la ley 30056 (2013), se ratifican estas facultades y se refuerza la potestad sancionadora de la CEB.

34 La UIT del año 2016 ha sido fijada en 3950 soles, de acuerdo al decreto supremo 397-2015-EF (2015).

35 Esto a través de las leyes 30056 (2013) y 30230 (2014).

36 Debe precisarse que, desde 2008 , las funciones de la CEB vinculadas a la eliminación de barreras burocráticas de alcance regional y/o local han sido desconcentradas gradualmente en las comisiones adscritas a 12 oficinas regionales del INDECOPI en el interior del país (véase la directiva 011-2013/ DIR-COD-INDECOPI). Sin embargo, la CEB mantiene plenas competencias sobre todas las entidades del Poder Ejecutivo (ministerios y organismos dependientes), autoridades locales y regionales de Lima y Callao, además de otras provincias, así como sobre toda otra persona de derecho público o privado que ejerza funciones administrativas. 


\section{PROBLEMÁTICA DE LAS REGULACIONES} MUNICIPALES EN SERVICIOS PÚBLICOS

La privatización de ciertos servicios públicos en el Perú, durante la década de 1990, no supuso una desaparición de la actuación del Estado en este tipo de mercados. Al igual que en Europa, los procesos de privatización dieron lugar a una forma distinta de intervención estatal que disminuyó la actuación del Estado prestador frente al surgimiento del Estado regulador (Majone, 1997). Bajo este modelo de intervención, los agentes privados que proveen de los servicios públicos entregados en concesión se encuentran regidos por determinadas reglas técnicas y económicas, derivadas del contrato de concesión suscrito con el Estado (Presidencia del Consejo de Ministros, 1996, artículo 25, último párrafo) (artículo 25 del Decreto Supremo 059-96-PCM)

, así como por las disposiciones normativas del sector y del organismo regulador correspondiente (Congreso de la República, 2000, artículo 3) (artículo 3 de la Ley 27332). Inclusive, en servicios aún no privatizados (como el suministro de agua potable y otros servicios de saneamiento), las empresas públicas también se encuentran sometidas a una regulación técnica y económica establecida por el regulador competente. Pese a la existencia de un marco regulatorio especial que rige la prestación del servicio (establecido y supervisado por el gobierno central), las empresas concesionarias de servicios públicos «en red» deben tener en cuenta, además, otro tipo de regulación cuyo origen y supervisión se encuentra a cargo de los gobiernos locales.

Los servicios de telecomunicaciones (telefonía fija, móvil e internet), así como la distribución de energía eléctrica, gas natural y agua potable, entre otros, requieren del despliegue de determinada infraestructura para la adecuada prestación del servicio (postes, ductos y tuberías, cableado, estaciones radioeléctricas, entre otros). A su vez, la existencia de esta infraestructura implica la realización de obras de instalación y/o mantenimiento en bienes de dominio público (como la reparación de roturas de pistas y veredas) o bienes que, aunque de propiedad privada, pueden afectar intereses públicos (como el tránsito de vehículos y personas, el urbanismo, el ornato y la seguridad en edificaciones, entre otros).

Debido a que el cuidado de estos intereses públicos ha sido asignado legalmente a los gobiernos locales, las empresas concesionarias $\longrightarrow$ las que están encargadas de instalar la infraestructura- deben obtener ciertas autorizaciones municipales de manera previa a las obras de despliegue de infraestructura. Así, la Ley Orgánica de Municipalidades (2003) atribuye a los gobiernos locales la posibilidad de exigir y normar el procedimiento de obtención de tres tipos de autorizaciones para el despliegue de infraestructura en servicios públicos, según se trate de

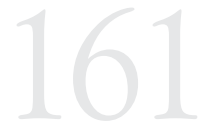

¿ES POSIBLE

HACER CUMPLIR

LA LEY SIN

SANCIONAR?

APLICANDO DE

MANERA

«RESPONSIVA» LA

REGULACIÓN EN

EL PERÚ

IS IT POSSIBLE

TO ENFORCE THE

LAW WITHOUT

SANCTIONING?:

APPLYING

REGULATION

WITH A

"RESPONSIVE"

APPROACH IN

PERU 
(i) la ejecución del plan de obras de servicios públicos que afecten o utilicen la vía pública o zonas aéreas (numeral 3.2. del artículo 79); (ii) la instalación de estaciones radioeléctricas; y/o, (iii) el tendido de cables (numeral 3.6.5. del artículo 79).

Sin perjuicio de lo señalado, la atribución municipal antes mencionada se encuentra delimitada por dos marcos normativos de alcance nacional que privilegian la simplificación administrativa y la uniformidad en los trámites. El primero está vinculado a las disposiciones generales y principios sobre creación, aprobación y difusión de procedimientos administrativos, así como al reconocimiento de derechos derivados de su tramitación, lo cual se encuentra recogido en la ley 27444 (LPAG). El segundo está vinculado a la regulación especial de los procedimientos de autorización por el despliegue de infraestructura de servicios públicos, recogida en el decreto legislativo 1014 (2008) y, en el caso específico del servicio de telecomunicaciones, en la ley 29022 (2007) ${ }^{37}$ (modificada por la ley 30228 (2014)) y su reglamento (2015).

La normativa antes mencionada tiene fuerza de ley y, por lo tanto, prevalece sobre cualquier otra norma de nivel local, en el entendido que se regula una materia de interés nacional como lo es la expansión de la infraestructura en servicios públicos y la simplificación de procedimientos. La razón de esta estandarización regulatoria en materias de procedimientos administrativos parece estar sustentada, además, en el principio de unidad de mercado, reconocido por el Tribunal Constitucional, según el cual el ejercicio de las actividades económicas en el territorio nacional no puede estar sujeto a regulaciones heterogéneas y diferenciadas según el espacio geográfico (2010, fundamento 9). Sobre la base de la mencionada legislación, es posible identificar, entre otras, las siguientes reglas de cumplimiento obligatorio para las municipalidades en los procedimientos para el despliegue de infraestructura de servicios públicos:

Reglas derivadas del procedimiento administrativo general:

- No puede exigirse documentación e información que ya posee o ha sido tramitada ante la misma municipalidad (LPAG, artículos 40 y 41$)$.

- El Texto Único de Procedimientos Administrativos (TUPA) debe haber sido aprobado por ordenanza debidamente publicada

37 Ley para el Fortalecimiento de la Expansión de Infraestructura en Telecomunicaciones (antes denominada Ley para la Expansión de Infraestructura en Telecomunicaciones, publicada el 20 de mayo de 2007). Dicha ley tuvo una vigencia de 4 años a partir de la vigencia del Reglamento, aprobado mediante decreto supremo 039-2007-MTC (2007). Posteriormente, el 29 de mayo de 2012, se publicó la ley 29868, que restableció la vigencia de la ley 29022 por un plazo de 4 años. Finalmente, el 12 de julio de 2014 se publicó la ley 30228 , que prorroga por 10 años la vigencia de la ley 29022 a partir de la vigencia de la ley 29868 (30 de mayo de 2012). 
(LPAG, artículo 36.1) y el contenido del TUPA debe ser publicado en los portales de la entidad y en el portal de servicios al ciudadano y empresas (LPAG, artículo 38).

- Únicamente puede exigirse aquello que ha sido consignado previamente en el TUPA de la municipalidad, siempre que los procedimientos y derechos de trámite en él contenidos hayan sido (Ley Orgánica de Municipalidades, artículos 40 y 44) (i) aprobados expresamente por ordenanza municipal; (ii) en el caso de los derechos, adicionalmente, deben haber sido ratificados por la municipalidad provincial.

- El monto del derecho de trámite por autorizaciones no puede exceder del costo real del servicio y no puede superar la Unidad Impositiva Tributaria (UIT) (LPAG, artículos 44 y 45).

- Únicamente pueden exigirse requisitos que sean necesarios y vinculados con la finalidad del procedimiento (LPAG, artículo 39).

Reglas generales para los servicios públicos en general ${ }^{38}$ :

- El uso de bienes de dominio público para el despliegue de infraestructura es gratuito (decreto legislativo 1014, artículo 3). Solo corresponde solicitar una autorización a la municipalidad correspondiente.

- El derecho de trámite que se cobre por la autorización de conexión domiciliaria no puede exceder del $1 \%$ de la UIT (decreto legislativo 1014, artículo 4) ${ }^{39}$.

- Los procedimientos sobre instalación de infraestructura en bienes públicos son de evaluación previa con silencio administrativo positivo, cumplido luego de transcurridos 5 días de presentada la solicitud (decreto legislativo 1014, artículo 5, modificado por la ley 30056 de 2011, artículo 5).

- Los procedimientos sobre instalación de infraestructura en bienes privados se rigen por el plazo general de 30 días hábiles de la LPAG (artículo $35^{\circ}$ ).

- Los requisitos para obtener las autorizaciones y las restricciones municipales para la realización de obras de infraestructura solo pueden estar relacionados a 4 aspectos (decreto legislativo 1014,

38 De acuerdo al artículo 2 del decreto legislativo 1014, los servicios públicos esenciales protegidos por dicho dispositivo son los siguientes:

a) Agua potable y alcantarillado,

b) transmisión y distribución de electricidad, así como alumbrado público,

c) gas natural,

d) telecomunicaciones.

39 La constitucionalidad de dicho dispositivo ha sido validada por el Tribunal Constitucional (2011).

¿ES POSIBLE

HACER CUMPLIR

LA LEY SIN

SANCIONAR?

APLICANDO DE

MANERA

«RESPONSIVA»LA

REGULACIÓN EN

EL PERÚ

IS IT POSSIBLE

TO ENFORCE THE

LAW WITHOUT

SANCTIONING?:

APPLYING

REGULATION

WITH A

"RESPONSIVE"

APPROACH IN

PERU 
artículo 6.2): (i) desarrollo urbanístico, patrimonio histórico o cultural de la Nación; y/o (ii) el medio ambiente.

- El desvío de tránsito para realizar alguna obra de infraestructura no requiere de una autorización. Para ello, basta con cursar una comunicación a la municipalidad competente, con la fecha y plan de desvío con una antelación de 7 días hábiles (decreto legislativo 1014, artículos 6.4, 6.5, 6.6).

Reglas especiales para el servicio público de telecomunicaciones ${ }^{40}$ :

- El procedimiento para obtener autorizaciones para instalación de infraestructura - sea en bienes públicos o privados- es de aprobación automática (no de evaluación previa) (artículo 5 de la ley 29022, modificada por la ley 30228).

- No puede exigirse mayores requisitos de los previstos en el reglamento de la ley 29022 (artículos 4 y 5 de la ley 29022, modificada por la ley 30228).

- El plan de ejecución de obras que exijan las municipalidades deberá ceñirse a las condiciones y requisitos establecidos en el reglamento de la ley, aprobado por el Poder Ejecutivo (Reglamento de la ley 29022, artículos 12, 14 y 15).

- La instalación de infraestructura puede realizarse sobre predios urbanizados, no urbanizados, eriazos, rústicos e inclusive que no cuenten con proyectos de habilitación urbana (ley 30228, tercera disposición complementaria y final).

Pese a las reglas de alcance nacional antes mencionadas, diversos gobiernos locales han emitido regulaciones que restringen la tramitación de autorizaciones para el despliegue de infraestructura de servicios públicos. De dichas regulaciones, las principales son las siguientes:

- Prohibición de instalar antenas de telefonía móvil y estaciones radioeléctricas en bienes de dominio público y privado.

- Imposición de plazos que superan los 5 días hábiles para la tramitación de procedimientos de despliegue de infraestructura.

- Imposición de procedimientos de evaluación previa cuando corresponde aprobación automática.

- Exigencia de requisitos que exceden la lista establecida en los artículos 12, 14 y 15 del Reglamento de la ley 29022, en el caso 
de instalación de infraestructura para la prestación del servicio de telecomunicaciones.

- Exigencia de tramitar autorizaciones de desvío de tránsito vehicular pese a que únicamente corresponde enviar una comunicación a la autoridad local competente.

- Exigencia de contar con licencia de edificación en el inmueble en el que se instale la infraestructura de telecomunicaciones.

- Exigencia de pagar un derecho de trámite en función de la extensión de la obra (metros lineales de cableado o ductos) o cantidad de elementos (postes, cámaras, entre otros), sin que ello esté relacionado con el costo del servicio administrativo.

Como se ha señalado en párrafos precedentes, la imposición de cargas administrativas costosas y de difícil cumplimiento desincentivan a los agentes económicos que desean acceder o permanecer en el mercado. En los servicios públicos, la imposición de regulaciones excesivas no solo tiene un impacto en la cantidad de ofertantes sino, además, en la propia cobertura del servicio, lo cual afecta la calidad y continuidad de estos. Teniendo en cuenta lo mencionado, resulta comprensible que la CEB del INDECOPI deba enfocar sus esfuerzos en mercados estratégicos como el de servicios públicos esenciales, además de que ello ha sido asignado expresamente como función de supervisión por el decreto legislativo 1014 y la ley 29022.

Debe tenerse en cuenta, sin embargo, que la labor de la CEB del INDECOPI enfrenta, en este sentido, una limitación importante: sus atribuciones no le permiten ordenar, vía un procedimiento iniciado de oficio, la eliminación con efectos generales de las barreras contenidas en ordenanzas municipales (LPAG, artículo 48). Pese a esta limitación, afortunadamente, la CEB puede utilizar mecanismos de disuasión efectivos, como la imposición de sanciones de hasta 20 UIT cuando verifique que una municipalidad viene aplicando — en la prácticaalguna barrera (i) considerada como infracción según el artículo 26BIS del decreto ley 25868; e (ii) identificada como ilegal y/o irrazonable en un precedente resolutivo de la CEB publicado en el Diario Oficial El Peruano.

Con las condiciones antes mencionadas, se requería que la CEB adopte una estrategia inteligente de enforcement que no involucre el uso indiscriminado de sus potestades sancionadoras (cuyo costo involucra no solo el procedimiento sancionador sino también el de ejecución coactiva) y que, a su vez, pudiera lograr una modificación con efectos generales en las regulaciones municipales. 


\section{VI. "REGULACIÓN RESPONSIVA»: FUNDAMENTOS Y PRINCIPIOS}

Tradicionalmente, se conocen dos estilos de enforcement o formas de hacer cumplir la ley; por un lado, la estrategia sancionadora o disuasiva («deterrence strategy») y, por otro lado, la estrategia persuasiva a través del consejo, negociación y/o coordinación («compliance strategy»o «adaptative strategy») (Black, 2001, p. 9; Hawkins; 1990; Gunningham, 2012). En el caso de la primera, se parte de la premisa de que las personas actúan racionalmente ante los incentivos generados por una sanción. De esa forma, se considera que la mayoría de sujetos regulados son seres «calculadores sin moral» (Kagan \& Scholz, 1984) que solo cumplirán la ley en la medida en que existan altas probabilidades de detección y cuando la sanción sea severa (Gunningham, 2012). En el caso del segundo tipo de estrategia, se prefiere la cooperación, negociación y diálogo entre el regulador y el regulado a fin de alcanzar el cumplimiento de las normas (Hawkins, 1984).

Frente a la pregunta «icómo hacer cumplir las leyes?», cabe hacerse una pregunta más realista: «ipor qué no funcionan o no se cumplen las leyes?» Según Robert Baldwin, las normas no funcionan cuando aquellos con voluntad de cumplirlas no saben qué implica cumplir (agentes bien intencionados pero mal informados) y cuando aquellos menos deseosos o capaces de cumplir (agentes bien/mal informados y mal intencionados) no están lo suficientemente estimulados para cumplirlas (1990, pp. 324ss.). Lo señalado implica que el éxito de una regulación parte del hecho de aceptar que no todos los agentes sujetos a ella reaccionan del mismo modo ni poseen los mismos incentivos o nivel de información.

Existe una estrategia que no requiere descartar o hacer prevalecer alguno de los mencionados estilos de enforcement y que, además, reconoce que los sujetos regulados pueden adoptar distintos comportamientos dependiendo de sus motivaciones, de la cultura de su entorno y del nivel de información, entre otros aspectos. A este tipo de técnica se lo ha conocido como regulación responsiva y consiste, principalmente, en que el regulador escale gradualmente una «pirámide de cumplimiento (enforcement pyramid) » al momento de buscar el cumplimiento de la ley, comenzando — desde la base — con acciones de persuasión, hasta llegar a la cumbre con medidas más punitivas o sancionadoras, según el tipo de respuesta y compromiso que pueda obtener del sujeto regulado (Ayres \& Braithwaite, 1992).

Así, a través de la interacción y la observación, el regulador es capaz de identificar a aquellos sujetos que tienen la predisposición de cumplir las leyes pero que requieren información sobre «cómo cumplirlas» o 
que están «en proceso de cumplirlas», frente a aquellos que, estando bien informados, voluntariamente incumplen las leyes. En el caso de los primeros, el envío de comunicaciones (prompt letters) puede originar un cambio en su comportamiento o un compromiso de mejora, con lo cual no se hace necesario seguir escalando la pirámide. En el caso del segundo tipo de sujetos mencionado, debido a su falta de cooperación con el modelo responsivo, corresponde seguir escalando la pirámide hacia medidas menos benignas, como la imposición de sanciones, hasta lograr que cumplan con la ley.

Básicamente, la composición de la pirámide propuesta por Ayres y Braithwate puede apreciarse en el siguiente gráfico (véase 1992, gráfico 2.1., p. 35):

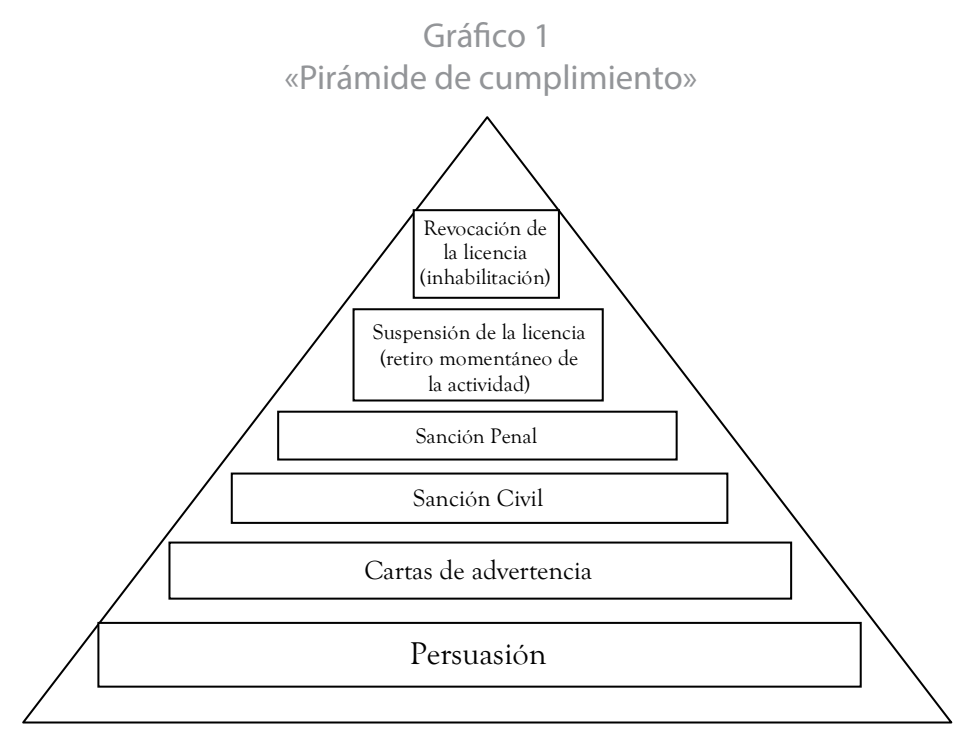

¿ES POSIBLE

HACER CUMPLIR

LA LEY SIN

SANCIONAR?

APLICANDO DE

MANERA

«RESPONSIVA» LA

REGULACIÓN EN

EL PERÚ

IS IT POSSIBLE

TO ENFORCE THE

LAW WITHOUT

SANCTIONING?:

APPLYING

REGULATION

WITH A

"RESPONSIVE"

APPROACH IN

PERU

Como precisan Ayres y Braitwaite, el éxito de la estrategia piramidal depende en gran medida de la posibilidad de contar con «grandes garrotes», además de con una variedad de métodos menos coercitivos (1992, p. 19), de tal manera que los reguladores puedan usar sus poderes sancionadores como «pistolas benignas» que solo sean usadas para disuadir e incapacitar a los mayores ofensores y persuadir a los sujetos que tienen la intención de cooperar y cumplir con la ley. Para aplicar adecuadamente esta estrategia, se han propuesto ciertos principios básicos a ser tomados en cuenta por las autoridades a cargo de una regulación (Braithwaite, 2011): 
1. Pensar en contexto; no imponer una teoría preconcebida.

2. Escuchar activamente, estructurando un diálogo que (i) dé voz a las partes interesadas; (ii) establezca objetivos comunes y la manera de monitorearlos; (iii) construya compromiso ayudando a los actores a encontrar una motivación propia para mejorar; y, (iv) comunique la firme decisión de supervisar la conducta hasta que el problema sea arreglado.

3. Hacer participar — con equidad — de la solución del problema a quienes se resisten a cumplir con la regulación, mostrándoles respeto y utilizando su resistencia como una oportunidad para mejorar la estrategia regulatoria.

4. Premiar a quienes muestran compromiso con el cumplimientodela regulación, ya sea (i) apoyando su innovación; (ii) «alimentando» su motivación para la mejora continua en su comportamiento; y, (iii) ayudando a los «líderes» del cumplimiento regulatorio a inspirar a los «rezagados» la existencia de nuevos límites de excelencia.

5. Señalar que, para alcanzar los objetivos, se preferirán métodos de apoyo y educación para construir mejores capacidades en los regulados.

6. Señalar - no amenazar inmediatamente- que existe un abanico de métodos que pueden ser utilizados escaladamente, precisando que las sanciones más severas serán usadas cuando sea necesario y como último recurso.

7. Emplear una gobernanza piramidal en red, involucrando no solo a la agencia reguladora sino a otros actores (públicos o privados) interesados en que se cumpla la ley y que puedan participar como socios estratégicos.

8. Provocar una «responsabilidad activa» que privilegia el cumplimiento de los objetivos regulatorios para futuros comportamientos, frente a la «responsabilidad pasiva», la cual mantiene el reproche sobre los actores responsables por comportamientos pasados.

9. Aprender y evaluar qué tan bien y a qué costo han sido obtenidos los objetivos regulatorios, comunicando finalmente las lecciones aprendidas.

Si bien se reconocen ciertas limitaciones y cuestionamientos a esta estrategia en cuanto a su aplicación práctica y consecuencias (Parker, 2006, pp. 613-617; Baldwin y Black, 2007, pp. 6-10; Gunningham, 2012), lo cierto es que propone un enfoque distinto dentro de las técnicas para hacer cumplir la ley, permitiendo que el regulador no actúe solo como 
una «máquina sancionadora» programada para castigar, sino como una autoridad que escucha, dialoga y observa a los sujetos involucrados con la regulación. Este enfoque también resulta importante en sistemas legales en los que la potestad sancionadora de las autoridades es cuestionada debido a los incentivos recaudatorios que estas últimas pueden tener. En este tipo de contexto, aplicar una técnica responsiva de escalamiento permite al regulador mostrar a la sociedad y al mercado que el objetivo principal del enforcement es el cumplimiento efectivo de la ley, antes que la imposición (y recaudación) de multas.

Más allá de las valoraciones antes mencionadas, la efectividad de una técnica de cumplimiento regulatorio solo es posible de ser comprobada a través de resultados verificados en la práctica. En ese sentido, la experiencia de la CEB en la adopción de una estrategia de coordinación y persuasión para el cumplimiento de ciertos objetivos regulatorios sirve como base para afirmar que la regulación responsiva puede ser efectiva en ciertos casos.

\section{ESTRATEGIA «RESPONSIVA» DE LA CEB Y RESULTADOS OBTENIDOS}

¿ES POSIBLE

HACER CUMPLIR

LA LEY SIN

SANCIONAR?

APLICANDO DE

MANERA

«RESPONSIVA» LA

REGULACIÓN EN

EL PERÚ

IS IT POSSIBLE

TO ENFORCE THE

LAW WITHOUT

SANCTIONING?:

APPLYING

REGULATION

WITH A

"RESPONSIVE"

La experiencia en la realización de investigaciones de oficio (normativa y de campo) a entidades públicas por parte del personal de la CEB APPROACH IN

PERU muestra que una de las razones principales por las que se imponen barreras burocráticas ilegales y/o carentes de razonabilidad — sobre todo a nivel de gobierno local — se relaciona con la falta de información y/o capacitación de los servidores públicos respecto del marco legal vigente en materia de simplificación de trámites y promoción de la iniciativa privada, más que con la mera voluntad de cometer una infracción a las leyes nacionales. Así, podría ser posible identificar distintos grupos de entidades a ser supervisadas, según su nivel de información, capacidad y voluntad de cumplimiento de la ley. Por tanto, la adecuación de las regulaciones municipales a la normativa nacional requiere de una estrategia de enforcement que sepa reconocer las limitaciones y capacidades de los agentes supervisados, utilizando las herramientas sancionadoras únicamente como último recurso.

A partir del año 2013, ya con las nuevas potestades sancionadoras de la CEB, se desarrolló una estrategia de investigación y supervisión que contempló las siguientes 4 etapas:

1.- Etapa de evaluación y diagnóstico

- Revisión de cada uno los TUPA y/u ordenanzas de las municipalidades distritales bajo jurisdicción de la CEB (Lima Metropolitana y el Callao) respecto de los procedimientos para 
obtener, entre otras, las autorizaciones para el despliegue de infraestructura en servicios públicos.

- Verificación sobre la vigencia del TUPA y/u ordenanza objeto de investigación.

- Evaluación de legalidad respecto de cada una de las exigencias, requisitos y/o cobros de los procedimientos antes mencionados, así como de las restricciones vinculadas a la actividad de despliegue de infraestructura.

- Identificación de las regulaciones posiblemente ilegales.

2.- Etapa informativa y de persuasión

- Envío de comunicaciones a las municipalidades sobre las posibles infracciones, en las que se les informaba lo siguiente:

i. Identificación de la posible infracción dentro de su TUPA y/u ordenanza.

ii. Marco normativo — de alcance nacional— que podría estar siendo vulnerado (posible infracción).

iii. Posible sanción por aplicar dicha regulación (hasta 20 UIT).

iv. Plazo para contestar sobre las acciones adoptadas sobre lo informado.

v. Posible sanción por no suministrar la información solicitada (hasta 50 UIT).

- Recepción de respuestas y feedback de las entidades, las cuales pueden clasificarse en:

i. Respuestas de compromiso: en la que la entidad acepta el diagnóstico realizado por la CEB y, en consecuencia, ofrece un futuro cambio (modificación o eliminación) en su regulación.

ii. Respuestas de adecuación: en la que la entidad comunica que ha adecuado su regulación con motivo de las recomendaciones efectuadas por la CEB.

iii. Respuestas de negativa de mejora: en la que la entidad manifiesta su oposición a las recomendaciones efectuadas, negándose a adecuar su regulación a las normas nacionales.

3.- Etapa de diálogo y coordinación

- En el caso de las respuestas de compromiso, la CEB inició un seguimiento regulatorio (o «regulatory tracking») que involucraba las siguientes actividades: 
i. Revisión diaria de los TUPA y/u ordenanzas de cada una de las municipalidades que ofrecieron una adecuación.

ii. Coordinaciones telefónicas con los servidores públicos involucrados con el ofrecimiento de adecuación, con la finalidad de verificar el estado del proceso de modificación normativa.

iii. De ser el caso, envío de nuevas comunicaciones, reiterando las posibles infracciones y recordando los compromisos de mejora.

\section{4.- Etapa responsiva por parte de la CEB}

- En el caso de las respuestas que evidencian una negativa a adecuarse a la ley, la CEB disponía, según fuera el caso, el inicio de los siguientes tipos de procedimientos:

i. Procedimiento administrativo sancionador en contra de la entidad, previo a la recolección de pruebas sobre la aplicación de las barreras burocráticas, cuando se trate de alguna de las 7 infracciones establecidas en el literal d) del artículo 26BIS del decreto ley $25868^{41}$; o,

ii. Procedimiento administrativo «declarativo» en contra de la entidad, con la finalidad de emitir, identificar y declarar oficialmente la ilegalidad y/o carencia de razonabilidad de la barrera burocrática investigada. Esta declaración, luego de ser publicada en el Diario Oficial El Peruano, conduce al inicio de un procedimiento sancionador en contra de los servidores públicos que apliquen tal barrera.

Es importante notar que la estrategia de investigación desplegada por la CEB coincide con el método de escalamiento piramidal desarrollado por Ayres y Braithwaite. En efecto, inicialmente, en la base de la pirámide se recurre al uso de cartas informativas que pueden persuadir a la municipalidad de modificar su normativa. En caso de no obtenerse

41 Las infracciones son las siguientes:

- Exigir requisitos adicionales a los máximos establecidos en la ley 28976 (Ley Marco de Licencia de Funcionamiento) y en la ley 29090 (Ley de Regulación de Habilitaciones Urbanas y de Edificaciones), o en aquellas disposiciones legales que las sustituyan o complementen. Exigir derechos de tramitación incumpliendo lo dispuesto por el artículo 45 de la LPAG o el artículo 70 del la Ley de Tributación Municipal.

- Incumplir la obligación establecida en el artículo 38.8 de la LPAG.

- Establecer plazos mayores a los señalados en los dispositivos legales que regulan el otorgamiento de licencias, autorizaciones y permisos, así como al despliegue para la ejecución y/o implementación de infraestructura en servicios públicos a que hacen referencia los numerales 2 y 3 del literal c) del artículo 26BIS.

- Aplicar regímenes de silencio administrativo sin observar lo dispuesto en la ley 29060 (Ley del Silencio Administrativo), o la ley que la sustituya.

- Exigir documentación y/o información prohibidas de solicitar conforme a los artículos 40 y 41 de la LPAG.

- Incumplir la obligación establecida en el numeral 126.2 del artículo 126 de la LPAG.

¿ES POSIBLE

HACER CUMPLIR

LA LEY SIN

SANCIONAR?

APLICANDO DE

MANERA

«RESPONSIVA» LA

REGULACIÓN EN

EL PERÚ

IS IT POSSIBLE

TO ENFORCE THE

LAW WITHOUT

SANCTIONING?:

APPLYING

REGULATION

WITH A

"RESPONSIVE"

APPROACH IN

PERU 
un compromiso de adecuación como respuesta, la CEB «asciende» a un segundo escalón que implica el inicio de un procedimiento - declarativo o sancionador, según corresponda-, luego del cual las municipalidades aún tienen la posibilidad de adecuar su conducta en el tiempo que dure el procedimiento. Finalmente, si es que durante el procedimiento no se obtuvo una respuesta satisfactoria o un cambio de comportamiento, se emite una resolución final mediante la cual: (i) se declara con carácter oficial la ilegalidad y/o carencia de razonabilidad de la regulación cuestionada; y (ii) se impone una sanción directamente a la municipalidad procesada o se procede a publicar la resolución para que, posteriormente, ante cualquier denuncia de parte, pueda sancionarse a los servidores públicos de la entidad por aplicar la barrera.

La estrategia antes descrita ha sido efectiva (probablemente no en términos de imposición de multas) en cuanto al logro de la eliminación - con efectos generales - de las regulaciones que fueron identificadas como presuntamente ilegales por la CEB. Desde junio del 2013 hasta diciembre del 2015 (30 meses), se reportaron 1137 barreras burocráticas eliminadas de manera voluntaria por parte de gobiernos locales, sin que haya sido necesaria la imposición de sanciones ${ }^{42}$. De este total, 483 correspondieron a barreras que afectaban la tramitación de autorizaciones para el despliegue de infraestructura en servicios públicos de telecomunicaciones, distribución de energía eléctrica, gas natural y agua potable. El hecho de que la adecuación antes descrita fue producto del monitoreo efectuado por la CEB se puede corroborar en la parte considerativa de algunas de las normas (decretos de alcaldía y ordenanzas) que aprobaban la modificación y/o derogación de las barreras investigadas previamente ${ }^{43}$. En efecto, dichos documentos reconocían que las comunicaciones cursadas por el INDECOPI (o el inicio de los procedimientos) sustentaban y motivaban el cambio normativo.

Este tipo de estrategia adoptado por la CEB no solo produce resultados a gran escala, sino que además genera ahorros para el mercado y promueve un uso eficiente de los recursos del Estado. En el caso de los agentes económicos, ha sido reportado en más de una oportunidad que la eliminación de barreras burocráticas puede generar ahorros millonarios (Mínguez, 2011; Coronado \& otros, 2014) ${ }^{44}$. En el caso

42 Esta cifra representa la cantidad de barreras eliminadas entre la etapa de investigación (antes del inicio formal de un procedimiento) hasta antes de la emisión de una resolución en la que se imponga una sanción o se declare formalmente la ilegalidad y/o irrazonabilidad de la barrera burocrática. Para mayor detalle, véase Secretaría Técnica de la CEB (2016)

43 Al respecto, ver Decreto de Alcaldía N 014-2014-ACL/MVES, de la Municipalidad Distrital de Villa El Salvador, publicado el 13 de agosto de 2014.

44 En un primer estudio, elaborado por Raúl Mínguez, se concluyó que las decisiones de la CEB en el año 2010 generaron un beneficio de aproximado S/. 15 MM (aprox. US\$ 4900 MM) para los agentes económicos beneficiados con la eliminación de las barreras identificadas. En un segundo estudio, usando una fórmula similar, la Gerencia de Estudios Económicos del INDECOPI estimó que la 
del Estado, el INDECOPI se beneficia en la utilización responsable de los procedimientos sancionadores, los cuales definitivamente generan mayores costos que la emisión de cartas informativas y la realización de llamadas telefónicas, por lo que los métodos punitivos deben ser utilizados solo como último recurso y como herramienta disuasiva (o «pistola benigna»), en tanto se tenga la capacidad de utilizar otros medios más efectivos.

En efecto, la tramitación de un procedimiento administrativo sancionador no solo implica el despliegue de actividades de análisis, investigación y decisión, durante un plazo máximo de 120 días hábiles en la CEB, sino que implica el inicio de procedimientos de ejecución coactiva para perseguir el cobro de la multa. Además, una actitud colaborativa con estrategias de persuasión y coordinación, como la adoptada por la CEB, puede generar un ahorro en gastos de defensa jurídica en el caso de las entidades supervisadas, además de evitar el pago de una multa que puede llegar hasta las 20 UIT.

El proceso de la estrategia descrito y los resultados obtenidos por la CEB, entre los años 2013 y 2015, han sido reconocidos como un caso exitoso por parte del ICN y el Banco Mundial en su reciente concurso de abogacía de la competencia a nivel mundial (véase la página web del Banco Mundial), especialmente por su impacto en sectores estratégicos para la economía peruana como el de infraestructura en servicios públicos. A juicio de los referidos organismos internacionales, la práctica peruana destaca por los resultados a gran escala obtenidos, a pesar de que la CEB no cuenta con poderes de derogación de normas. Asimismo, la ICN y el Banco Mundial reconocen implícitamente que la actividad de control regulatorio de la CEB tiene un importante impacto en la defensa de la competencia al permitir que los agentes que desean ingresar o permanecer en el mercado vean eliminadas las barreras administrativas que obstruyen dichos fines.

Finalmente, más allá de los resultados obtenidos por la CEB, será importante determinar a través de la práctica y de la investigación si es que esta estrategia de enforcement puede ser replicada con éxito en otro tipo de órganos resolutivos y de supervisión (no solo dentro del INDECOPI, sino dentro de la administración pública en general). Para ello, debe tenerse en cuenta que cada ambiente regulatorio posee distintas características, ya sea por el marco legal que lo rige, el tipo de autoridad reguladora y sus atribuciones, los sujetos regulados, las partes interesadas, entre otros aspectos. Afortunadamente, la esencia de la regulación responsiva consiste en observar a los elementos y sujetos antes descritos, adoptando acciones según los mensajes y

¿ES POSIBLE

HACER CUMPLIR

LA LEY SIN

SANCIONAR?

APLICANDO DE

MANERA

"RESPONSIVA» LA

REGULACIÓN EN

EL PERÚ

IS IT POSSIBLE

TO ENFORCE THE

LAW WITHOUT

SANCTIONING?:

APPLYING

REGULATION

WITH A

"RESPONSIVE"

APPROACH IN

PERU 
comportamientos que se muestren en el mercado, partiendo de valores esenciales como el respeto, el diálogo, el uso eficiente de recursos y la coordinación entre Estado, empresa y ciudadanos.

\section{CONCLUSIONES}

Del presente documento es posible extraer las siguientes conclusiones:

1. La actividad regulatoria sobre los agentes económicos puede afectar la cantidad de ofertantes en el mercado; sin embargo, la legislación sobre defensa de la competencia usualmente no incluye métodos punitivos para conductas regulatorias, sino que ofrece un mecanismo de naturaleza consultiva y de persuasión, denominado «abogacía de la competencia».

2. Una de las principales limitaciones de una estrategia de abogacía de la competencia es su carácter no vinculante sobre las autoridades públicas.

3. El modelo de control regulatorio en el Perú resulta sorprendente a nivel comparado debido a que la autoridad de competencia peruana, a través de la $\mathrm{CEB}$, posee como atribuciones las siguientes: (i) la emisión de mandatos de eliminación (general y particular) de las regulaciones identificadas como ilegales y/o irrazonables; y, (ii) la imposición de sanciones a los servidores públicos y entidades que desacaten sus mandatos y/o que infrinjan determinadas leyes $\mathrm{y} / \mathrm{o}$ precedentes vinculantes.

4. La CEB posee un amplio ámbito de supervisión; sin embargo, en los últimos 3 años, consideró necesario priorizar los esfuerzos de investigación en sectores estratégicos como los servicios públicos esenciales (telecomunicaciones, distribución de energía eléctrica, agua potable y gas natural), con la finalidad de verificar que no se impongan barreras burocráticas ilegales y/o irrazonables por parte de los gobiernos locales.

5. La labor de la CEB enfrenta una limitación importante. Sus atribuciones no le permiten ordenar, vía un procedimiento iniciado de oficio, la eliminación con efectos generales de las barreras burocráticas contenidas en ordenanzas. Por lo tanto, se requiere la adopción de una estrategia de enforcement que no involucre el uso indiscriminado de sus potestades sancionadoras y que, a su vez, pueda lograr un efecto general en las regulaciones municipales.

6. La «regulación responsiva» es una estrategia de enforcement que consiste, principalmente, en que el regulador escale gradualmente una «pirámide de medidas» al momento de buscar el cumplimiento 
de la ley, comenzando desde la base con acciones de persuasión y consejo hasta llegar a la cumbre con medidas más punitivas o sancionadoras, según el tipo de respuesta y compromiso que pueda obtener del sujeto regulado.

7. Una las razones principales por las que se imponen barreras burocráticas ilegales y/o irrazonables — sobre todo a nivel municipal - es la falta de información y/o capacitación de los servidores públicos respecto del marco legal vigente en materia de simplificación de trámites y promoción de la inversión privada, antes que por la mera voluntad de cometer una infracción.

8. En su actividad de supervisión sobre las municipalidades de Lima y Callao en materia de eliminación de regulaciones innecesarias para el despliegue de infraestructura en servicios públicos, la CEB adoptó una estrategia que coincide con el método de escalamiento piramidal desarrollado por Ayres y Braithwaite.

9. La CEB recurrió al uso de cartas informativas para persuadir a las municipalidades de modificar su normativa. Si es que durante la investigación o procedimiento no se obtenía una respuesta satisfactoria o un cambio de comportamiento, se procedía a la emisión de una resolución final sancionadora o con orden de publicación para una posible sanción.

10. La estrategia adoptada por la CEB dio como resultado la eliminación voluntaria de más de 1000 barreras burocráticas en menos de 3 años, de las que más del 40\% (483) corresponden a regulaciones que afectaban el mercado de infraestructura de servicios públicos.

11. El proceso de la estrategia descrito y los resultados obtenidos en la CEB entre los años 2013 y 2015 fueron reconocidos como un caso exitoso por parte del ICN y el Banco Mundial en su reciente concurso de abogacía de la competencia a nivel mundial, especialmente por su impacto en sectores estratégicos para la economía peruana, como el sector de infraestructura en servicios públicos, entre otros.

12. El reto siguiente en la aplicación de la «regulación responsiva» en el Perú consiste en determinar a futuro — a través de la práctica y de la investigación - si es que esta estrategia de enforcement puede ser replicada con éxito a otro tipo de oficinas, no solo dentro del INDECOPI, sino dentro de la administración pública en general. 


\section{BIBLIOGRAFÍA}

Ayres, Ian \& John Braithwaite (1992). Responsive regulation. Oxford: Oxford University Press.

Baldwin, Robert (1990). Why rules don't work. Modern Law Review, 53(3), 321-337.

Baldwin, Robert \& Julia Black (2007). Really responsive regulation. Londres: London School of Economics.

Banco Mundial. The 2015-2016 Competition Advocacy Contest. How to build a culture of competition for private sector development and economic growth. http://www.worldbank.org/en/events/2015/10/30/the-2015--2016-competition-advocacy-contest-how-to-build-a-culture-of-competition-for-private-sector-development-and-economic-growth\#5.

Black, Julia (2001). Managing discretion. En Penalties: policy, principles and practice in government regulation. ALRC Conference Papers.

Bork, Robert H. (1993). The antitrust paradox: a policy at war with itself. Nueva York: Basic Books.

Braithwaite, John (2011). The essence of responsive regulation. UBC Law Review, 44, 475-520.

Cambridge University Press (2016). Cambridge Dictionaries Online. http:// dictionary.cambridge.org/dictionary/english/.

Cecot, Caroline \& otros (2008). An evaluation of the quality of impact assessment in the European Union with lessons for the US and the EU. Regulation and Governance, 2 (4), 405-424.

Congreso de la República (2000). Ley Marco de los Organismos Reguladores de la Inversión Privada en los Servicios Públicos. Ley 27332. Diario Oficial El Peruano, 29 de julio.

Congreso de la República (2001). Ley del Procedimiento Administrativo General. Ley 27444. Diario Oficial El Peruano, 11 de abril.

Congreso de la República (2003). Ley Orgánica de Municipalidades. Ley 27972. Diario Oficial El Peruano, 27 de mayo.

Congreso de la República (2007a). Ley Marco de Licencia de Funcionamiento. Ley 28976. Diario Oficial El Peruano, 5 de febrero.

Congreso de la República (2007b). Ley de Eliminación de Sobrecostos, Trabas y Restricciones a la Inversión Privada. Ley 28996. Diario Oficial El Peruano, 4 de abril.

Congreso de la República (2007c). Ley para la Expansión de Infraestructura en Telecomunicaciones. Ley 29022. Diario Oficial El Peruano, 20 de mayo.

Congreso de la República (2007d). Ley del Silencio Administrativo. Ley 29060.

Diario Oficial El Peruano, 7 de julio. 
Congreso de la República (2007e). Ley de Regulación de Habilitaciones Urbanas y de Edificaciones. Ley 29090. Diario Oficial El Peruano, 25 de setiembre.

Congreso de la República (2012). Ley que restablece la vigencia de la Ley 29022: Ley para la Expansión de Infraestructura en Telecomunicaciones. Diario Oficial El Peruano, 29 de mayo.

Congreso de la República (2013). Ley que modifica diversas leyes para facilitar la inversión, impulsar el desarrollo productivo y el crecimiento empresarial. Ley 30056. Diario Oficial El Peruano, 2 de julio.

Congreso de la República (2014a). Ley que establece medidas tributarias, simplificación de procedimientos y permisos para la promoción y dinamización de la inversión en el país. Ley 30230. Diario Oficial El Peruano, 12 de julio.

Congreso de la República (2014b). Ley que modifica la Ley 29022, Ley para la Expansión de Infraestructura en Telecomunicaciones. Ley 30228. Diario Oficial El Peruano, 12 de julio.

Coronado, Javier \& otros (2014). Midiendo el costo económico potencial de las barreras burocráticas en el Perú. Observatorio de Mercados, 8(16).

Emberger, Geraldine (2006). How to strengthen competition advocacy through competition screening. Competition Policy Newsletter (Opinions and Comments), 1, pp. 28-32.

Gunningham, Neil (2012). Chapter 7: Enforcement and compliance strategies. En Robert Baldwin y otros (eds.). The Oxford handbook of regulation (pp. 120145). Oxford: Oxford University Press.

Hann, Robert W. \& Patrick Dudley (2007). How well does the government do cost-benefit analysis? Review of Environmental Economics and Policy, 1(2), 192-211.

Hawkins, Keith (1984). Compliance Strategy. En Environment and enforcement: regulation and the social definition of pollution. Oxford: Oxford University Press.

Hawkins, Keith. (1990) «Compliance strategy, prosecution policy and aunt Sally». British Journal of Criminology, 30(4), 444-466.

Hovenkamp, Herbert J. (1985). Antitrust policy after Chicago. Michigan Law Review, 84, 213-284.

ICN (2002). Advocacy and Competition Policy. ICN's Conference. Naples, Italy. México: Comisión Federal de Competencia.

ICN (2009a). ICN factsheet and key messages. http://www.internationalcompetitionnetwork.org/uploads/library/doc608.pdf

ICN (2009b). Report on Assessment of ICN Members' Requirements and Recommendations on Further ICN Work on Competition Advocacy. Presented at the 8th Annual Conference of the ICN (Zurich, June 2009).

INDECOPI (1997). Resolución 186-97-TDC-INDECOPI. 
INDECOPI (2007a). Resolución 0019-2007/CAM-INDECOPI.

INDECOPI (2007b). Resolución 1493-2007/TDC-INDECOPI.

INDECOPI (2008a). Resolución 0013-2008/CAM-INDECOPI.

INDECOPI (2008b). Resolución 1692-2008/TDC-INDECOPI.

INDECOPI (2010). Resolución 3065-2010/SC1- INDECOPI.

INDECOPI (2012). Resolución 0334-2012/CEB- INDECOPI.

INDECOPI (2013a). Directiva 011-2013/DIR-COD-INDECOPI.

INDECOPI (2013b). Resolución 0459-2013/CEB-INDECOPI.

INDECOPI (2013c). Resolución 1232-2013/SDC- INDECOPI.

INDECOPI (2014a). Resolución 0017-2014/CEB- INDECOPI.

INDECOPI (2014b). Resolución 0143-2014/CEB-INDECOPI.

INDECOPI (2014c). Resolución 0170-2014/CEB-INDECOPI.

INDECOPI (2015a) Resolución 0368-2015/CEB-INDECOPI.

INDECOPI (2015b). Resolución 0188-2015/SDC-INDECOPI.

INDECOPI (2015c). Resolución 0194-2015/CEB-INDECOPI.

INDECOPI (2015d). Resolución 0226-2015/SDC-INDECOPI.

INDECOPI (2015e). Resolución 0271-2015/SDC-INDECOPI.

INDECOPI (2015f). Resolución 0284-2015/SDC-INDECOPI.

INDECOPI (2015g). Resolución 0340-2015/SDC- INDECOPI.

INDECOPI (2015h). Resolución 0453-2015/CEB-INDECOPI.

INDECOPI (2015i). Resolución 0513-2015/SDC-INDECOPI.

Ivec, Mary \& Valerie Braithwaite (2015). Application of responsive regulatory theory in Australia and overseas: update. Canberra: Regulatory Institutions Network-Australian National University.

Jones, Alison \& Brenda Sufrin (2014). EU Competition Law. Text, cases, and materials. Quinta edición. Oxford: Oxford University Press.

Kagan, Robert A. y John T. Scholz (1984). The «criminology of the corporation» and regulatory enforcement strategies. En Keith Hawkins y John Thomas (eds.), Enforcing regulation (pp. 67-95). Boston: Kluwer-Nijhoff.

Majone, Giandomenico (1997). From the Positive to the Regulatory State: causes and consequences of changes in the mode of governance. Journal of Public Policy, 17(2), 139-167.

Mínguez, Raúl (2011). Estudio de medición del impacto de las barreras burocráticas en el mercado. Lima: Programa COMPAL-Proyecto para el Perú. 
Ministerio de Comercio Exterior y Turismo (2004). Reglamento de Restaurantes. Decreto supremo 025-2004-MinceTUR. Diario Oficial El Peruano, 10 de noviembre.

Ministerio de Transportes y Comunicaciones (2007). Reglamento de la ley 29022: Ley para la Expansión de Infraestructura en Telecomunicaciones. Decreto supremo 003-2015-MTC. Diario Oficial El Peruano, 13 de noviembre.

Ochoa Mendoza, Francisco J. (2015). Fundamentos del procedimiento de eliminación de barreras burocráticas. Revista de la Competencia y de la Propiedad Intelectual, 19 (10), 1-56.

OECD (2003) The objectives of competition law and policy. OECD Global Forum on Competition. http://www.oecd.org/daf/competition/2486329.pdf.

OECD (2008) Introductory handbook for undertaking regulatory impact analysis. París: OECD Publishing.

OECD (2009). Regulatory Impact Analysis. A Tool for Policy Coherence. París: OECD Publishing.

Parker, Christine (2006). The «compliance» trap: the moral message in responsive regulatory enforcement. Law $\mathbb{E}$ Society Review, 40(3), 591-622.

Presidencia de la República (1992). Ley de Organización y Funciones del Instituto Nacional de Defensa de la Competencia y de la Protección de la Propiedad Intelectual -INDECOPI. Decreto ley 25868. Diario Oficial el Peruano, 24 de noviembre.

Presidencia de la República (1996). Facultades, Normas y Organización del INDECOPI. Decreto legislativo 807. Diario Oficial El Peruano, 18 de abril.

Presidencia de la República (2008a). Decreto legislativo que establece medidas para propiciar la inversión en materia de servicios públicos y obras públicas de infraestructura. Decreto Legislativo 1014. Diario Oficial El Peruano, 16 de mayo de 2008.

Presidencia de la República (2008b). Decreto Legislativo que aprueba la Ley de Organización y Funciones del Instituto Nacional de Defensa de la Competencia y de la Protección de la Propiedad Industrial-INDECOPI. Decreto legislativo 1033. Diario Oficial El Peruano, 25 de junio.

Presidencia de la República (2008c). Decreto legislativo que aprueba la Ley de Represión de Conductas Anticompetitivas. Decreto legislativo 1034. Diario Oficial El Peruano, 25 de junio.

Presidencia de la República (2015a). Reglamento de la ley 30228. Decreto supremo 003-2015-MTC. Diario Oficial El Peruano, 18 de abril.

Presidencia de la República (2015b). Decreto legislativo que refuerza las facultades sobre eliminación de barreras burocráticas para el fomento de la competitividad. Decreto legislativo 1212. Diario Oficial El Peruano, 24 de setiembre. 
Presidencia de la República (2015c). Decreto supremo que aprueba la Unidad Impositiva Tributaria (UIT) para el año 2016. Decreto supremo 397-2015-EF. Diario Oficial El Peruano, 24 de diciembre.

Presidencia del Consejo de Ministros (1996). Texto único ordenado de las normas con rango de ley que regulan la entrega en concesión al sector privado de las obras públicas de infraestructura y de servicios públicos. Decreto Supremo 059-96-PCM. Diario Oficial El Peruano, 27 de diciembre.

Presidente de los Estados Unidos (1993). Executive Order 12866. 58 FR 51735, 4 de octubre.

Quintana, Eduardo (2011). El objetivo de la ley de competencia peruana y la interpretación de las conductas prohibidas. Revista de la Competencia y de la Propiedad Intelectual, 13(7), 19-59.

Secretaría Técnica de la CEB (2016). Listado de barreras burocráticas eliminadas por acciones de la CEB. https://www.indecopi.gob.pe/web/eliminacion-debarreras-burocraticas/informacion-util

Tribunal Constitucional (2010). Sentencia recaída en el expediente 000142009-AI. Alcalde de la Municipalidad Metropolitana de Lima (demandante) contra Congreso de la República (demandado). 25 de agosto.

Tribunal Constitucional (2011). Sentencia recaída en el expediente 00031 2010-AI. Municipalidad Metropolitana de Lima contra el Poder Ejecutivo. 23 de mayo. 